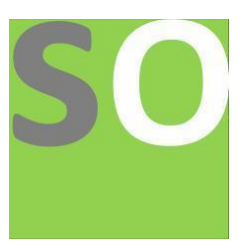

Article title: Performance Investigation of a Permanent Magnet DC Machines using Robust Control

Technique

Authors: Mustefa Jibril[1], Messay Tadese[2], Fiseha Bogale[3]

Affiliations: School of Electrical and Computer Engineering[1], Department of mechanical Engineering[2]

Orcid ids: 0000-0002-3165-2410[1]

Contact e-mail: mustefazinet1981@gmail.com

License information: This work has been published open access under Creative Commons Attribution License http://creativecommons.org/licenses/by/4.0/, which permits unrestricted use, distribution, and reproduction in any medium, provided the original work is properly cited. Conditions, terms of use and publishing policy can be found at https://www.scienceopen.com/.

Preprint statement: This article is a preprint and has not been peer-reviewed, under consideration and submitted to ScienceOpen Preprints for open peer review.

DOI: 10.14293/S2199-1006.1.SOR-.PPJRJCO.v1

Preprint first posted online: 21 October 2020

Keywords: Permanent magnet Dc motor, Permanent magnet Dc generator, $\mathrm{H} 2$ optimal controller, $\mathrm{H}$ infinity synthesis controllers 


\title{
Performance Investigation of a Permanent Magnet DC Machines using Robust Control Technique
}

\author{
Mustefa Jibril $^{1}$, Messay Tadese ${ }^{2}$, Fiseha Bogale ${ }^{3}$ \\ ${ }^{1}$ Msc, School of Electrical \& Computer Engineering, Dire Dawa Institute of Technology, Dire Dawa, \\ Ethiopia \\ ${ }^{2}$ Msc, School of Electrical \& Computer Engineering, Dire Dawa Institute of Technology, Dire Dawa, \\ Ethiopia \\ ${ }^{3}$ Msc, Department of Mechanical Engineering, Kombolcha Institute of Technology, Wollo, Ethiopia \\ mustefa.jibril@ddu.edu.et
}

\begin{abstract}
In this paper, the design and performance investigation of the permanent magnet machines have been done to increase the mechanical and electrical outputs improvement of the systems. A permanent magnet Dc motor (PMDM) and generator (PMDG) have been modelled and designed to improve the angular position and generated current respectively. In this work, augmentation based $\mathrm{H} 2$ optimal and $H \propto$ synthesis controllers have been designed as a controller for the two systems and a comparison between the proposed controller for tracking a reference inputs and a promising results have been obtained.
\end{abstract}

Keywords: Permanent magnet Dc motor, Permanent magnet Dc generator, H 2 optimal controller, $H \infty$ synthesis controllers

\section{Introduction}

The permanent magnet machines have the benefit of getting an excitation from the permanent magnet which is found at the stator part of the machines in order to get some efficiency benefit for that. Induction machines have a good and regulated fluxes that's why it is helpful to optimize the efficiency. Both systems are used for variable-speed drive. The specification of the performance and efficiency of the permanent magnet machine better has better cost minimization function with optimal for the range and performance target. In this paper, the modeling design and control of a permanent magnet Dc motor and generator for improving the angular speed and generating current have been done using robust control theory.

\section{Mathematical Modelling}

2.1 Permanent Magnet DC Motor Modelling

Consider the cross section of a motor shown in Figure 1 below that has several loops of wire. 


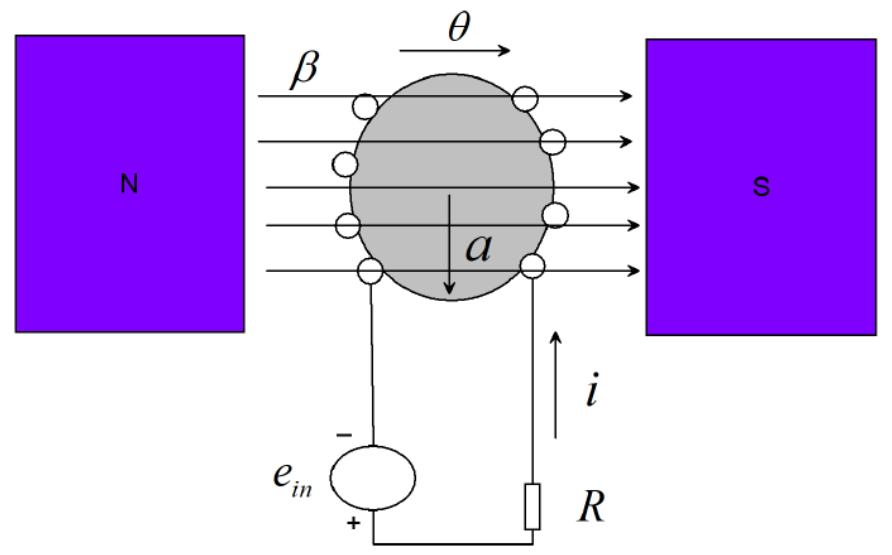

Figure 1 PMDM cross section

The static magnetic field formed by a electromagnet with strength $\beta$ going from left to right (North to South). The thickness of the magnet is defined by $\ell$. The loops of the wire around a "rotor" which is an iron cylinder with radius "a" that is free to rotate about its center. There are " $\mathrm{n}$ " rounds of wire with current going into the page on the right side, and comes out of the page to the right). The rotational angle, $\theta$, is positive in the clockwise direction, the resistance of the wire is given by $\mathrm{R}$. The moment of inertia of the rotor, "J," with friction of rotation "Br." The mathematical model for this system is derived by separating the system as mechanical system and the electrical system as shown in Figure 2 below.
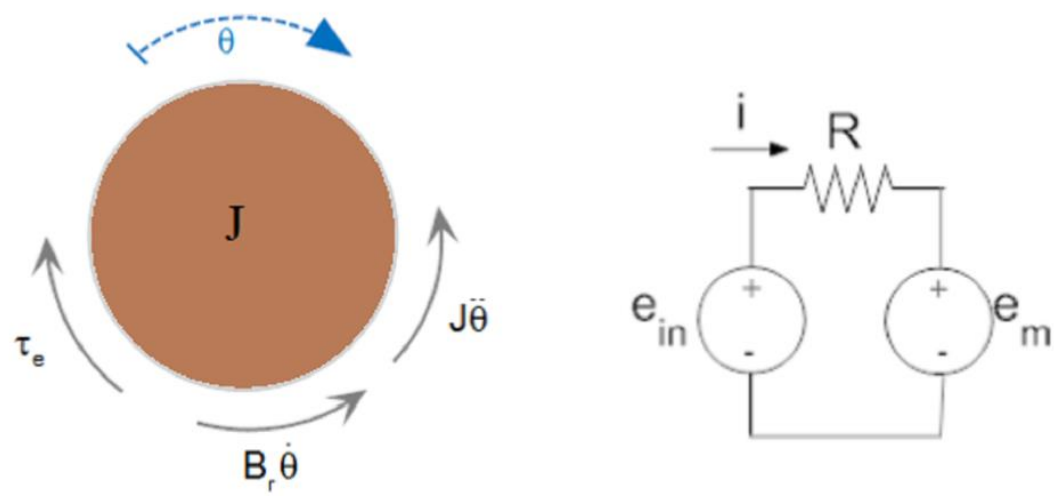

Figure 2 Mechanical and electrical systems

The torque developed in the loop of wire is given by

With a back emf

$$
\begin{aligned}
& \tau_{e}=2 \text { nail } \beta=\alpha i \\
& \alpha=2 \text { nal } \beta
\end{aligned}
$$

$$
e_{m}=2 n \omega a l \beta=\alpha \omega
$$

The electrical source is the input to the and the mechanical torque is the output of the motor From the mechanical body diagram we get

$$
J \ddot{\theta}+B_{r} \dot{\theta}=\tau_{e}=\alpha i
$$

and from the electrical free diagram we get 


$$
e_{i n}-i R=e_{m}=\alpha \omega
$$

Substituting Equation (3) for current into Equation (4) yields:

$$
e_{i n}-\frac{J \ddot{\theta}+B_{r} \dot{\theta}}{\alpha} R=\alpha \omega=\alpha \dot{\theta}
$$

Taking the Laplace transform with initial conditions set to zero and solve for the ratio of output to input yields:

$$
\frac{\Theta(s)}{E_{\text {in }}(s)}=\frac{\alpha}{J R s^{2}+\left(B_{r} R+\alpha^{2}\right) s}
$$

The parameters of the PMDM is shown in Table 1 below.

Table 1 PMDM parameters

\begin{tabular}{|c|c|c|c|}
\hline No & Parameter & Symbol & Value \\
\hline 1 & Resistance of the Wire & $\mathrm{R}$ & $10 \mathrm{ohm}$ \\
\hline 2 & Moment of inertia of the rotor & $\mathrm{J}$ & $0.8 \mathrm{Kgm}^{2} / \mathrm{s}^{2}$ \\
\hline 3 & Friction of rotation & $B_{r}$ & $1.2 \mathrm{Nms}$ \\
\hline & Motor specification & $\alpha$ & 1.8 \\
\hline
\end{tabular}

The transfer function numerically becomes

$$
\frac{\Theta(s)}{E_{\text {in }}(s)}=\frac{1}{4.44 s^{2}+8.47 s}
$$

\subsection{Permanent Magnet DC Generator Modelling}

A permanent magnet DC generator is typically the same machine as a motor. The motor uses a mechanical input and generates an electrical output.

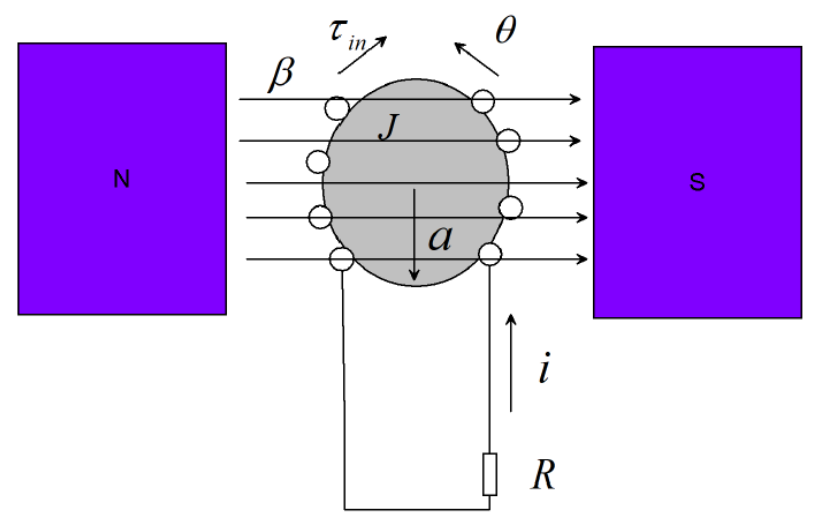

Figure 3 PMDG cross section

The free body diagram of the mechanical and electrical system is shown in Figure 4 below. In this system consideration of the direction of the induced torque is essential. The positive current is coming out of the page on the left side of the rotor and the field is to the right. The back emf, is in the positive direction with counterclockwise direction of the wires on the left side have positive velocity downward. 


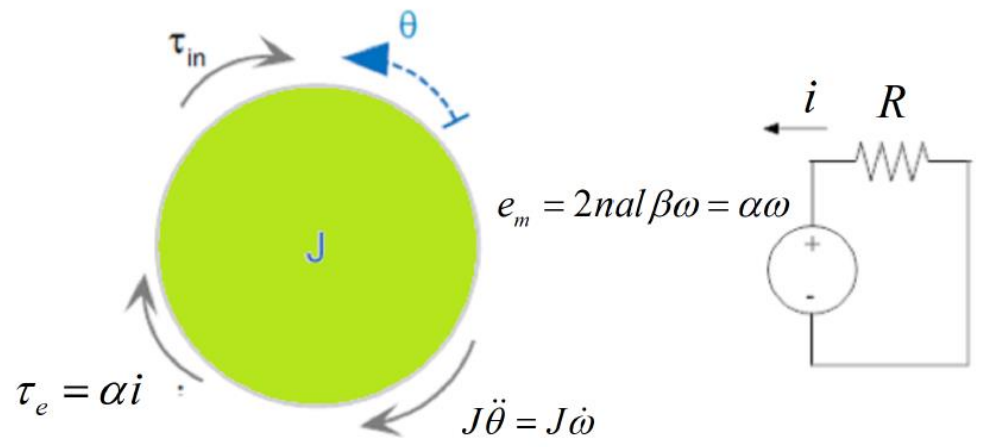

Figure 4 Mechanical and electrical systems

$$
\begin{gathered}
\tau_{e}+\tau_{i n}+J \dot{\omega}=0 \\
\alpha i+\tau_{i n}+J \dot{\omega}=0 \\
e_{m}+i R=0 \\
\alpha \omega+i R=0
\end{gathered}
$$

Taking the Laplace Transform of Equation (6) and Equation (7) and eliminating the angular velocity, $\omega(s)$ yields:

$$
\frac{I(s)}{T_{i n}(s)}=\frac{\alpha}{J R s+\alpha^{2}}
$$

The parameters of the PMDG is shown in Table 2 below.

Table 2 PMDG parameters

\begin{tabular}{|c|c|c|c|}
\hline No & Parameter & Symbol & Value \\
\hline 1 & Resistance of the Wire & R & $15 \mathrm{ohm}$ \\
\hline 2 & Moment of inertia of the rotor & $\mathrm{J}$ & $0.6 \mathrm{Kgm}^{2} / \mathrm{s}^{2}$ \\
\hline 3 & Motor specification & $\alpha$ & 2.9 \\
\hline
\end{tabular}

The transfer function numerically becomes

$$
\frac{I(s)}{T_{i n}(s)}=\frac{1}{3.1 s+2.9}
$$

\section{Proposed Controllers Design}

\subsection{Augmentations of the Model with Weighting Functions}

The weighted control structure of the systems is shown in Figure 5, where $W 1(s), W 2(s)$, and $W 3(s)$ are weighting functions. The assumption that $G(s), W 1(s)$, and $W 3(s) G(s)$ are all proper systems. The weighting function $W 3(s)$ is not required to be proper system. In the state space structure of the systems, the output vector $\mathrm{y} 1=[\mathrm{y} 1 \mathrm{a}, \mathrm{y} 1 \mathrm{~b}, \mathrm{y} 1 \mathrm{c}] \mathrm{T}$ cannot be used directly to the control signal u. Clearly, Figure 5 represents a more general picture of optimal and robust control systems. The design of the $\mathrm{H} 2$ optimal and $H \propto$ synthesis controllers is done by using the idea of the augmented state space model. 


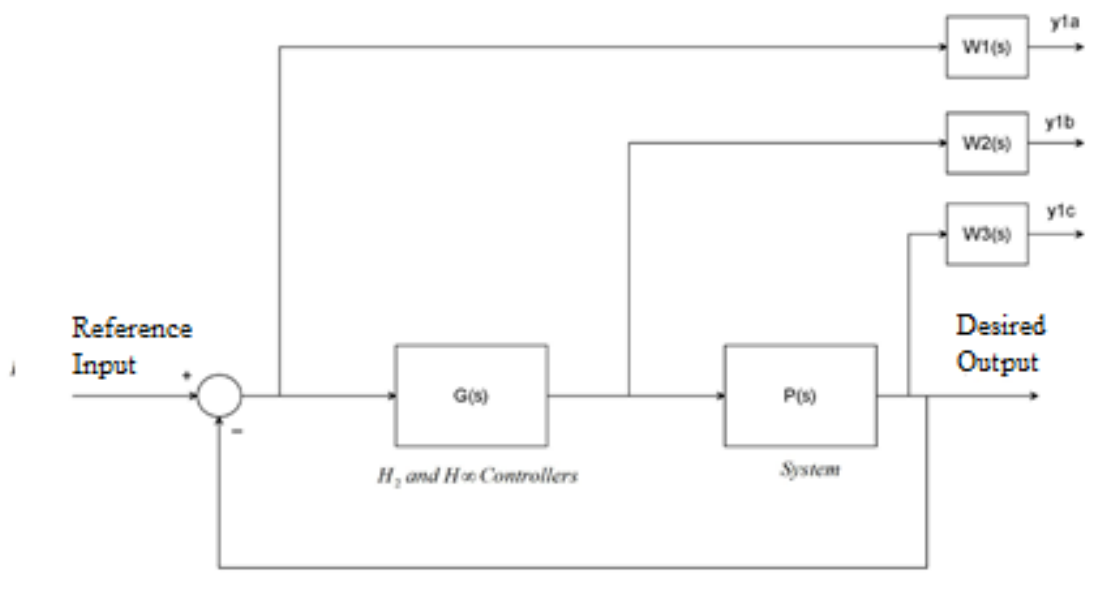

Figure 5 weighted control structure with the proposed controllers

\section{For the motor}

The weighting function $\boldsymbol{W} 1 \mathrm{~m}(s), \boldsymbol{W} 2 \mathrm{~m}(s)$, and $\boldsymbol{W} 3 \mathrm{~m}(s)$ are chosen as

$$
W_{1 m}(s)=\frac{s+1}{2 s+5} \quad W_{2 m}(s)=\frac{s+8}{3 s+24} \quad W_{3 m}(s)=7
$$

The H 2 optimal controller become

$$
G_{m H_{2}}=\frac{3.1679 s^{2}+11.3466 s+41.7504}{s^{3}+47.1659 s^{2}+125.7358 s+28.2287}
$$

The $H \infty$ synthesis controller become:

\section{For the generator}

$$
G_{m H_{\infty}}=\frac{3.26 s^{2}+12.2 s+28.38}{s^{3}+47.2 s^{2}+128.6 s+27.6}
$$

The weighting function $\boldsymbol{W} 1 \mathrm{~g}(s), \boldsymbol{W} 2 \mathrm{~g}(s)$, and $\boldsymbol{W} 3 \mathrm{~g}(s)$ are chosen as

$$
W_{1 g}(s)=\frac{s+4}{s+8} \quad W_{2 g}(s)=\frac{s+12}{2 s+14} \quad W_{3 g}(s)=9
$$

The H 2 optimal controller become

$$
G_{g H_{2}}=\frac{2.5736 s+12.0904}{s^{2}+5.2298 s+18.7438}
$$

The $H \propto$ synthesis controller become:

$$
G_{g H_{\infty}}=\frac{3.2096 s+18.3848}{s^{2}+8.6176 s+17.4376}
$$




\section{Result and Discussion}

4.1 Comparison of a PMDM with $\mathrm{H} 2$ Optimal and $H \propto$ Synthesis Controllers for Improving the Angular Position using a Step Reference Angular Position Input

The angular position output of a PMDM performance analysis is done by simulating the system with the proposed controllers for a step input reference input and the simulation result is shown in Figure 6 below.

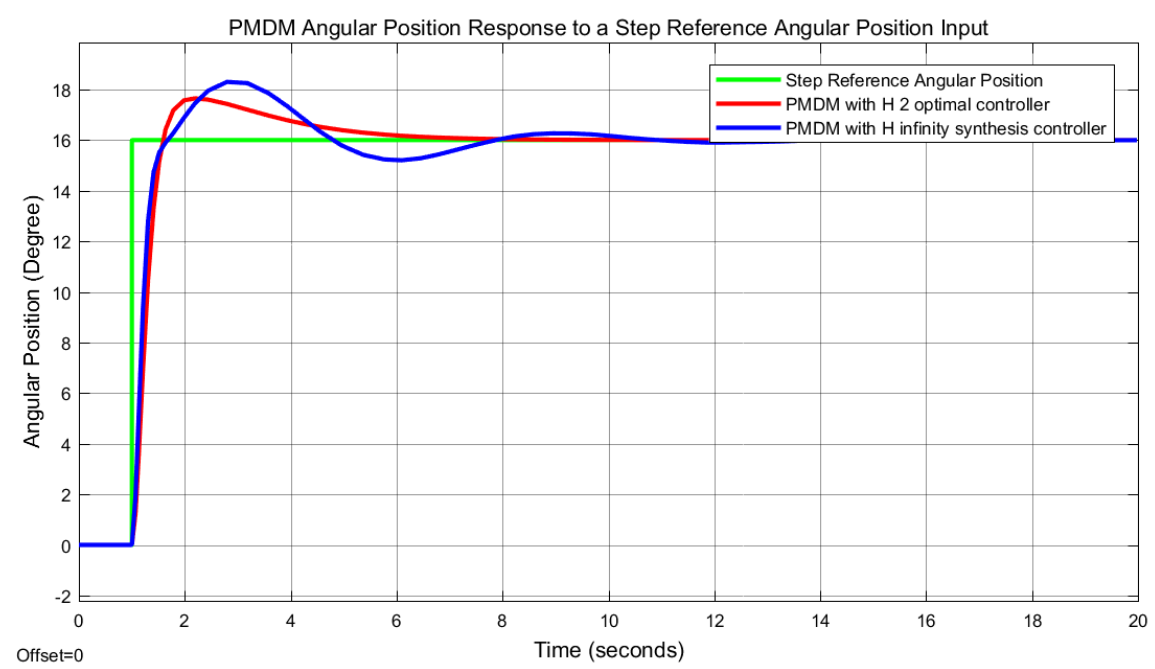

Figure 6 Step response of the PMDM

The simulation result shows that the PMDM with $\mathrm{H} 2$ optimal controller improves the angular position in minimizing the percentage overshoot and the settling time better than the system with $H \propto$ synthesis controller.

4.2 Comparison of a PMDM with $\mathbf{H} 2$ Optimal and $H \infty$ Synthesis Controllers for Improving the Angular Position using a Random Reference Angular Position Input The angular position output of a PMDM performance analysis is done by simulating the system with the proposed controllers for a random input reference input and the simulation result is shown in Figure 7 below.

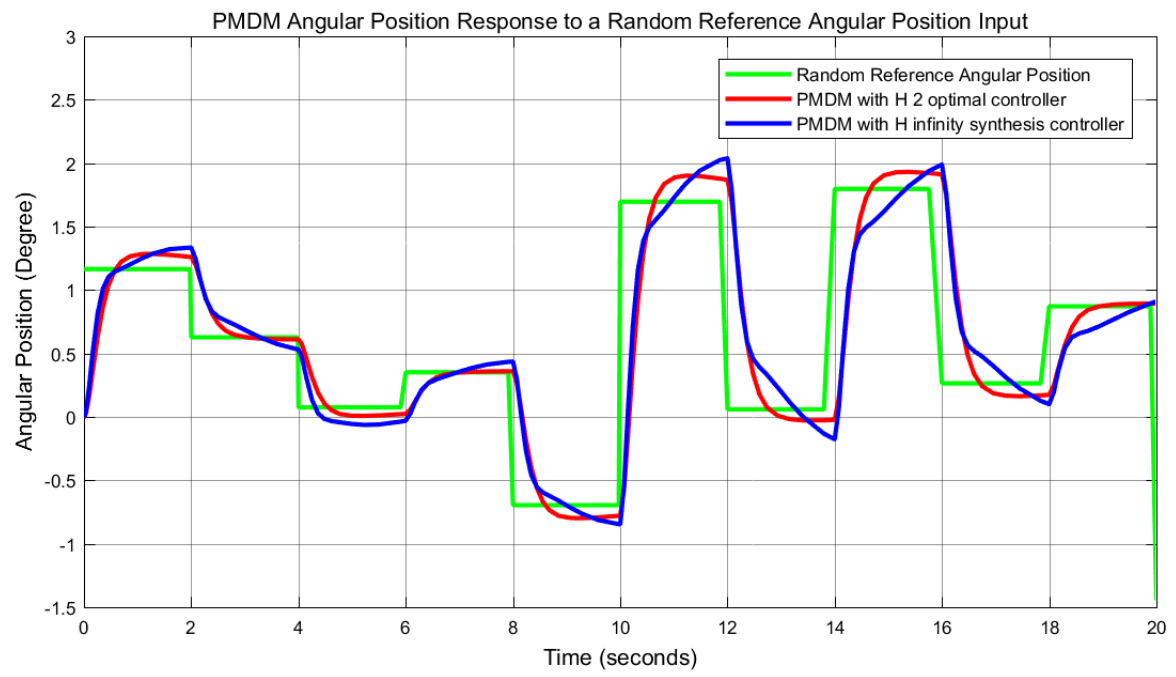

Figure 7 Random response of the PMDM 
The simulation result shows that the PMDM with $\mathrm{H} 2$ optimal controller improves the angular position in tracking the reference input signal with better amplitude than the system with $H \infty$ synthesis controller.

\subsection{Comparison of a PMDG with H 2 Optimal and $H \infty$ Synthesis Controllers for Improving the Generating Current using a Step Reference Current Input}

The angular position output of a PMDG performance analysis is done by simulating the system with the proposed controllers for a step input reference input and the simulation result is shown in Figure 8 below.

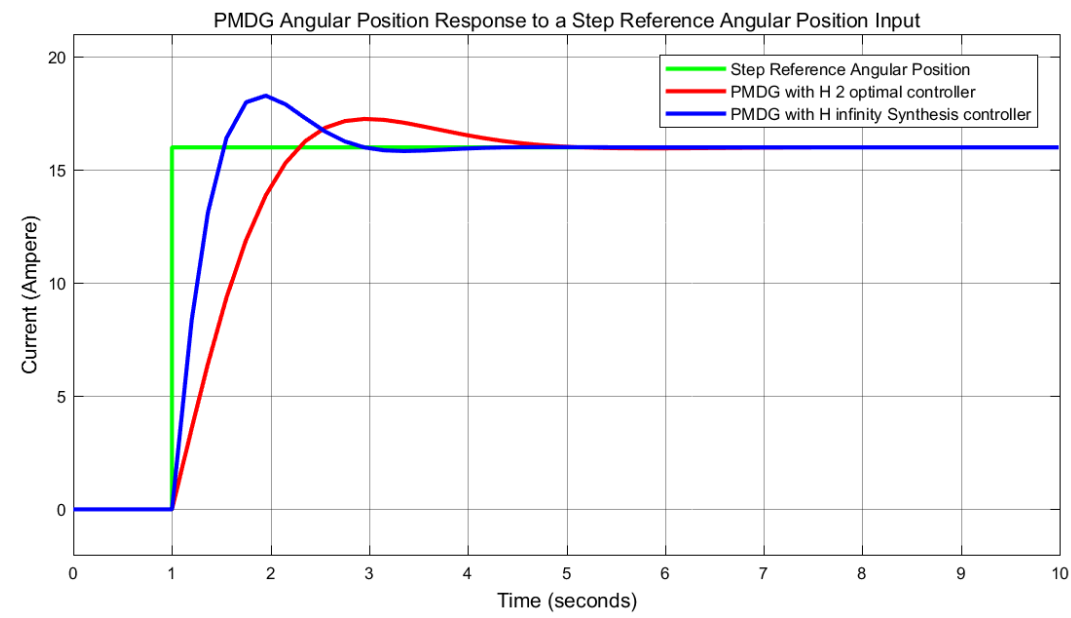

Figure 8 Step response of the PMDG

The simulation result shows that the PMDG with $\mathrm{H} 2$ optimal controller improves the generating current in minimizing the percentage overshoot better than the system with $H \propto$ synthesis controller.

4.4 Comparison of a PMDM with $\mathbf{H} 2$ Optimal and $H \infty$ Synthesis Controllers for Improving the Generating Current using a Random Reference Current Input

The angular position output of a PMDM performance analysis is done by simulating the system with the proposed controllers for a random input reference input and the simulation result is shown in Figure 9 below.

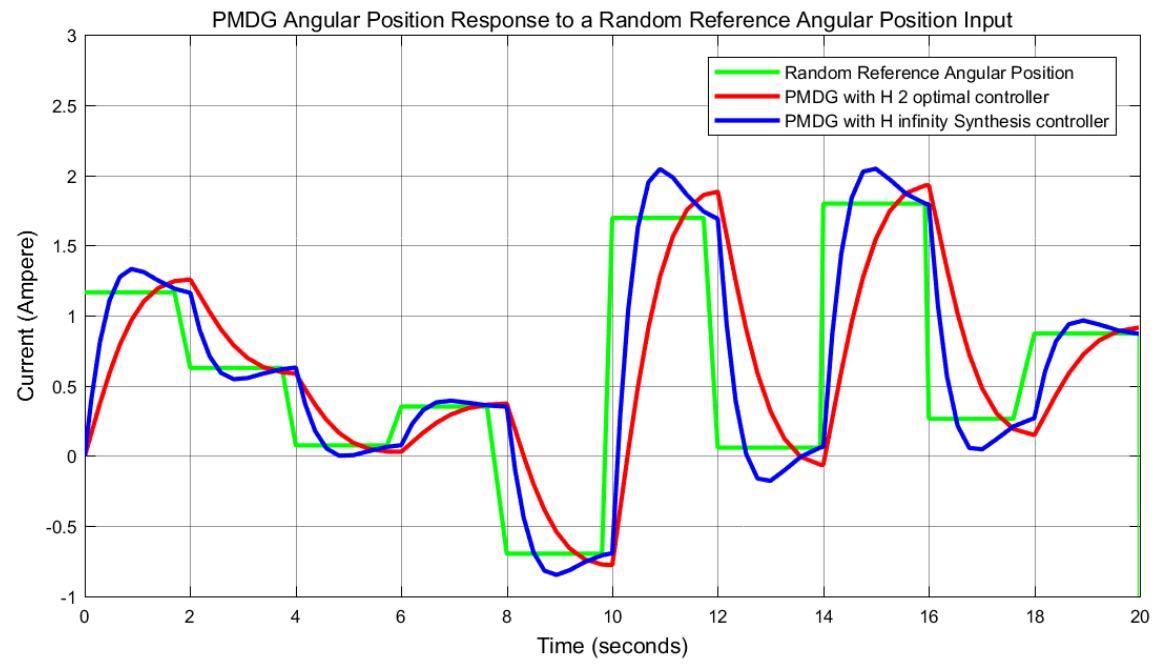

Figure 9 Random response of the PMDG 
The simulation result shows that the PMDG with $\mathrm{H} 2$ optimal controller improves the angular position in tracking the reference input signal with better amplitude than the system with $H \infty$ synthesis controller.

\section{Conclusion}

The modelling, design and control of a permanent magnet Dc motor for an improvement of angular position and a permanent magnet Dc generator for improving of the generating current using augmentation based $\mathrm{H} 2$ optimal and $H \propto$ synthesis controllers. A comparison of the proposed systems with the proposed controllers for the analysis of the performance improvement of the angular position and generating current using a step and random reference input signals. The simulation result of the PMDM for a step reference angular position input suggested that the PMDM with $\mathrm{H} 2$ optimal controller improves the angular position in minimizing the percentage overshoot and the settling time while the simulation result of the PMDM for a random reference angular position suggested that the PMDM with $\mathrm{H} 2$ optimal controller improves the angular position in tracking the reference input signal with better amplitude. The simulation results of the PMDG suggested that the PMDG with $\mathrm{H} 2$ optimal controller improves the generating current in minimizing the percentage overshoot for a step input reference current and the PMDG with $\mathrm{H} 2$ optimal controller improves the angular position in tracking the reference input signal with better amplitude.

\section{Reference}

[1]. Mustefa Jibril et al. "Design and Simulation of a Steam Turbine Generator using Observer Based and LQR Controllers" Researcher, Vol. 12, Issue 6, pp. 13-17, 2020.

[2]. Mustefa Jibril et al. "Design and Simulation of Voltage Amplidyne System using Robust Control Technique" Researcher, Vol. 12, Issue 8, pp. 17-21, 2020.

[3].K. S. Belkhir "Simple Implementation of a Fuzzy Logic Speed Controller for a PMDC Motor with a Low Cost Arduino Mega" Engineering, Technology \& Applied Science Research, Vol. 10, No. 2, 2020.

[4]. Hasanpour D. et al. "Identification and Adaptive Position and Speed Control of Permanent Magnet DC Motor with Dead Zone Characteristics Based on Support Vectors Machines" Journal of Control, Vol. 13, No. 2, pp. 53-66, 2019.

[5].Zeng Song et al. "Review on Control of Permanent Magnet Brushless DC Motor for Electric Vehicle" International Journal of Electric and Hybrid Vehicles, Vol. 10, No. 4, 2018.

[6].Fadhil R. T. et al. "Analysis and Stabilization of Chaos in Permanent Magnet DC Motor Driver" International Journal of Bifurcation and Chaos, Vol. 27, No. 11, 2017.

[7]. Niasar A. et al. "Design and implementation of a Low Cost Maximization Power Conversion System for Brushless DC Generator" Ain Shams Engineering Journal, Vol. 8, Issue 4, pp. 571-580, 2017.

[8]. Kuigang Shen et al. "Design and Research of Modular Permanent Magnet DC Generator Based on Magnetic Integrated Transformer for Offshore Wind Farm" The Journal of Engineering, Vol. 2017, Issue 13, 2017.

[9].Louar Fateh et al. "Modeling and Control of a Permanent Magnet Synchronous Generator Dedicated to Standalone Wind Energy Conversion System” Journal of Frontiers in Energy, Vol. 10, Issue 1, pp. 155-163, 2016. 